\title{
Certezas, incertidumbres, posibilidades y desafios. La pandemia de Covid-1 9 en la educación en Argentina
}

\author{
Certainties, uncertainties, possibilities and challenges. \\ The Covid-19 pandemic in education in Argentina
}

\section{Certezas, incertezas, possibilidades e desafios. A pandemia de Covid-I 9 na educação na Argentina}

Pablo Ariel Scharagrodsky'

https://orcid.org/0000-000 I-6305-2017

\begin{abstract}
Resumen: El artículo analiza la llegada de la Covid-19 a la Argentina en un contexto de fuerte desigualdad social. En dicho escenario indaga las diferentes políticas educativas realizadas con el fin de garantizar el acompañamiento del proceso educativo $y$, al mismo tiempo, disminuir el impacto desigual que está generando la pandemia. Reflexiona, a partir de la teoría social crítica, acerca de algunas certezas e incertidumbres que acontecen en los espacios virtuales y digitales $y$, al mismo tiempo, invita a pensar y experimentar las múltiples posibilidades y desafíos que la pandemia ofrece con el fin de revisar, potenciar y desnaturalizar los modos en que acontece el hecho educativo.
\end{abstract}

Palabras clave: Pandemia. Certezas educativas. Desafíos educativos.

Summary: The article analyzes the arrival of Covid-19 in Argentina, in a context of strong social inequality. In this scenario, it investigates the different educational policies carried out in order to guarantee the accompaniment of the educational process and, at the same time, reduce the uneven impact that the pandemic is generating. Based on critical social theory, the article reflects on some certainties and uncertainties that occur in virtual and digital spaces and, at the same time, invites to think and experience the multiple possibilities and challenges that the pandemic offers in order to review, enhance and denature the ways in which the educational event occurs.

Keywords: Pandemic. Educational certainties. Educational challenges.

Resumo: $O$ artigo analisa a chegada da Covid-19 na Argentina em um contexto de forte desigualdade social. Investiga as diferentes políticas educacionais realizadas para garantir o acompanhamento do processo educacional

\footnotetext{
I Doutor em Ciências Sociais e Humanas pela UNQ- Universidad Nacional de Quilmes (Argentina). Docente da Universidad Nacional de Quilmes e Universidad Nacional de La Plata. E-mail: pas@unq.edu.ar.
}

Olhar de professor, Ponta Grossa, v. 24, p. I-9, e-15582.025, 2021.

Disponível em <https://revistas2.uepg.br/index.php/olhardeprofessor> 
e, ao mesmo tempo, reduzir o impacto desigual que a pandemia está gerando. Investiga, com base na teoria social crítica, sobre algumas certezas e incertezas que ocorrem nos espaços virtuais e digitais e, ao mesmo tempo, convida a pensar e experimentar as múltiplas possibilidades e desafios que a pandemia oferece para revisar e desnaturalizar as maneiras pelas quais o processo educacional ocorre.

Palavras-chave: Pandemia. Certezas educacionais. Desafios educacionais.

\section{Introducción}

Hace cerca de ciento cincuenta años la población de la ciudad de Buenos Aires atravesó una de las peores epidemias de fiebre amarilla, la cual provocó miles de muertos e importantes cambios sociales, culturales, demográficos y políticos. Durante el siglo $X X$ se sumaron otras importantes enfermedades que alteraron o modificaron el orden social, como la epidemia de poliomielitis, o la transmisión de la tuberculosis, la viruela, el sarampión, el cólera, el chagas y el dengue. Pero ninguna de estas enfermedades es posible de ser comparada con la Covid-19. Cada epidemia es única, resultante de un microrganismo y del modo en que una sociedad la confronta, reacciona e interpreta (ARMUS, 2020). La escala transnacional del fenómeno, los efectos en la organización social, política y económica mundial, la recurrencia y la forma en que los medios de comunicación están enunciando -y produciendo- la pandemia, los prolongados confinamientos de millones de personas, la implementación como nunca antes de políticas masivas estatales de ayuda laboral, económica, social, alimentaria, etc. y la cada vez mayor interdependencia entre los países afectados, son alguno de los aspectos que ubican al virus en una dimensión socio-política -y diplomática- inusitada y, al mismo tiempo, configuran un escenario con consecuencias inciertas y desconocidas.

En este complejo contexto transnacional, a partir del 20 de marzo, las autoridades argentinas solicitaron a las personas que habitaban en el país -o se encontraran en él-, en forma temporaria o definitiva, que debían realizar el aislamiento social, preventivo y obligatorio para evitar el contagio² (RAMACCIOTTI, 2020). Esta decisión generó todo un conjunto de modificaciones en los estilos de vida de la población no solo en lo relativo a la higiene individual y colectiva, sino en la vida social, cultural y política más amplia. Los sistemas educativos -públicos y privados- no fueron ajenos a dichas exigencias, cambios y transformaciones. En la Argentina, la Covid-19 afectó a más de 10 millones de estudiantes y casi 900 mil docentes de nivel inicial, primario y secundario. La pandemia llegó con una intensidad material y simbólica inusual, generando una serie de preguntas, demandas, consultas, interpelaciones, incertidumbres, certezas, desafíos y posibilidades en el mundo educativo actual. En este contexto, a partir de principios generales de la teoría social crítica en educación (GIROUX, 2003) y retomando un enfoque comprensivo e interpretativo, el objetivo del ensayo es pensar la Covid-19

\footnotetext{
${ }^{2}$ A diferencia de otros países, el actual gobierno argentino ha priorizado la salud individual y colectiva frente a otro tipo de razones o intereses. Las palabras del presidente, Alberto Fernández, fueron contundentes: 'De la economía se vuelve, de la muerte no se vuelve más'.
} 
como un significante que articula diversos sentidos en el campo educativo, que exceden a la enfermedad orgánica y cuya “(...) interpretación -parcial y precaria- (...) está abierta” (SOUTHWELL, 20I8, p. 67) a múltiples (in)certezas, interrogantes -y posibilidades de acción- político-pedagógicas.

\section{Entre certezas e incertidumbres}

En la Argentina, como en muchos países del planeta, la pandemia ha visibilizado -como se ha hecho hace muchas décadas de la mano de diversas posiciones teóricas- que los diversos y heterogéneos sistemas educativos, en sus diferentes niveles y regiones, siguen presentando fuertes desigualdades de acceso, tránsito y acreditación en términos de clase social, grupo social, capital cultural, género, orientación sexual, etnia, región geográfica, etc., etc., etc. Pero este persistente escenario, con matices y resistencias, ha operado de manera diferente dependiendo la ideología política del gobierno de turno. Por ejemplo, si tomamos las últimas dos décadas, las importantes políticas educativas de inclusión, educación digital y ampliación de derechos en la Argentina durante el período 2003-20I5 fueron, durante la gestión de Cambiemos entre el 2015-2019, desatendidas, cuestionadas o, inclusive, desmanteladas. En este último período los indicadores de pobreza, indigencia, desigualdad, desempleo y precarización laboral aumentaron muy fuertemente. En el plano educativo, entre 2016 y 2018 la inversión nacional cayó un $9 \%$ en términos reales y el poder adquisitivo del salario docente descendió $14 \%$ entre 2015 y 2018 , con fuertes disparidades entre las provincias. Es en este contexto de pauperización social, sanitaria ${ }^{3}$ y educativa que arribó la pandemia a la Argentina, agravando aún más las desigualdades de todo tipo, incluidas las vinculadas con el universo pedagógico y el acceso a la virtualidad. Existe un fuerte consenso que indica que los indicadores de desempleo, pobreza, indigencia, vulnerabilidad social y psicológica están aumentando muy fuertemente producto de la pandemia. ${ }^{4}$ Frente a semejante escenario, las políticas educativas nacionales y provinciales concretaron una serie de acciones con el fin de 'achatar' la brecha de desigualdad y fragmentación social y educativa $y$, al mismo tiempo, garantizar y acompañar el proceso educativo. Por ejemplo, todas las provincias impulsaron contenidos pedagógicos, el $45 \%$ amplió la infraestructura digital de sus estudiantes, más del

\footnotetext{
${ }^{3}$ La coalición Cambiemos (2015-2019) transformó el Ministerio de Salud Pública en Secretaría. Con esta medida, esta dependencia estatal pasó a estar bajo la tutela del Ministerio de Desarrollo Social, lo que llevó implícito una reducción de la autonomía en la gestión y de partidas presupuestarias. También, se redujo la entrega de anticonceptivos gratuitos en los centros de salud, se dificultó el acceso a las vacunas contra el sarampión y la Gripe A y se desmanteló gran parte de las prestaciones de salud destinadas a la tercera edad (RAMACCIOTTI, 2020).

${ }^{4}$ Según la Comisión Económica para América Latina y el Caribe (Cepal) la Covid-19 conducirá a la peor contracción que la región ha sufrido desde 1914 y 1930 . Pronosticó que la caída promedio rondará el 5,3\% en la región y que la Argentina sufrirá una disminución de su PBI del 6,5\% en el 2020 (CEPAL, 2020).
}

Olhar de professor, Ponta Grossa, v. 24, p. I-9, e-15582.025, 2021.

Disponível em <https://revistas2.uepg.br/index.php/olhardeprofessor> 
Certezas, incertidumbres, posibilidades y desafios. La pandemia de Covid-1 9 en la educación en Argentina $60 \%$ impulsó políticas de capacitación docente para el contexto de pandemia, el 100\% implementó o incrementó acciones de apoyo a la inclusión educativa vinculadas al servicio alimentario y más de un tercio de las jurisdicciones propusieron iniciativas de acompañamiento específico a familias y jóvenes (CARDINI; D'ALESSANDRE; TORRE, 2020). Estas políticas muestran a los actores de la trama educativa asumiendo acciones concretas ${ }^{5}$ acompañadas de un fuerte compromiso social y colectivo. Sin embargo, las certezas sobre políticas educativas activas en un escenario de mayor deterioro y vulnerabilidad social encuentran varias preguntas e incertidumbres en el campo educativo nacional y provincial. Entre ellas algunas se destacan. Aún no sabemos qué tipo de afectación generará este desigual e injusto contexto socio-político en las relaciones, intercambios y en las experiencias educativas y pedagógicas en las diferentes y heterogéneas provincias de la Argentina. Tampoco sabemos cómo continuará el escenario escolar cuando la situación se 'normalice', ya que serán muchas las decisiones que se deberán tomar tanto a nivel micro como macro (acreditaciones, etc.).

A este juego de certezas e incertidumbres producidas en el contexto social más amplio, es posible sumar otras de diversa índole. Por un lado, se destaca la idea fuertemente consensuada en las agendas y políticas educativas trans-nacionales que la producción, transmisión, distribución y circulación del bien social educativo se debe realizar en el marco de condiciones socio técnicas particulares (DUSSEL, 2020) donde el mundo virtual y digital se ha convertido en texto y contexto a la vez. La Covid-19 ha virtualizado, a gran escala y como nunca antes, los procesos educativos de enseñanza y aprendizaje generando nuevas configuraciones de sentido con relación a la experiencia educativa y a las formas de aprender $y$ enseñar. Si bien sabemos que las plataformas virtuales donde interactuamos con los y las estudiantes nos posibilitan conectarnos de cierta manera con ellos, intercambiar saberes y opiniones, acompañarlos, y aprender nuevos sentidos sobre la realidad social, hay muchas dudas e interrogantes sobre aquellos y aquellas que no pueden acceder a los espacios virtuales $^{6}$, así como el tipo de interacción emocional, corporal y kinética que se genera en las plataformas virtuales en un contexto tan excepcional como es el de la pandemia.

\footnotetext{
${ }^{5}$ Entre las múltiples acciones son posibles mencionar las siguientes: "el Ministerio de Educación de la Nación lanzó el programa 'Seguimos Educando'. A través de la Televisión Pública se difunden contenidos educativos para nivel inicial, primario y secundario. Se han elaborado cuadernillos con actividades disponibles de forma online. Asimismo, todas las provincias desarrollaron plataformas para distribuir contenidos digitales. Se facilitó la navegación gratuita en todo el país y se entregaron 135.000 netbooks y tablets para alumnos de escuelas secundarias. También se concretaron políticas de acompañamiento a docentes a través de cursos y capacitaciones docentes. Por otra parte, se reforzaron las políticas alimentarias a los estudiantes en estado de vulnerabilidad" (CARDINI; D'ALESSANDRE; TORRE, 2020, p. 5-9).

${ }^{6}$ Existe una enorme disparidad de conexión y de oferta a espacios virtuales entre las provincias argentinas. Entre las menos favorecidas se encuentran Santiago del Estero, Formosa, Catamarca, San Juan o Corrientes. Esta brecha se profundiza fuertemente de acuerdo al estrato social de origen de los y las estudiantes.
} 
Por otro lado, en este juego de certezas e incertezas es posible mencionar que a pesar de aceptar y ponderar los potenciales beneficios pedagógicos de los entornos virtuales a la hora de enseñar y aprender, el formato digital no reemplaza al formato escolar tradicional. Es decir, más allá del potencial que poseen las nuevas tecnologías en educación, el formato espacio temporal educativo presencial permite ciertas experiencias corporales, kinéticas, proxémicas, afectivas o de participación e intercambio que el formato digital aún no puede concretar. En este punto, la dimensión espacial es central para el proceso educativo, ya que "el lugar proporciona el marco dentro del cual comprendemos cualquier forma de aparición" e interacción humana (MALPAS, 20I5, p. 209-210). Sus condiciones materiales y simbólicas particulares potencian, estimulan y, al mismo tiempo, limitan u obstaculizan múltiples posibilidades. El aula, el patio, los pasillos, la entrada de la escuela, los baños, la sala de biblioteca, el salón de docentes, la sala de regencia, el lugar de la fotocopia, el 'kiosco' o el espacio vinculado a la práctica deportiva son espacios absolutamente diferentes a los del hogar. En los primeros acontecen relaciones, situaciones, prácticas, rituales, rutinas, experiencias y sensaciones físicas (olernos, abrazarnos, escucharnos, mirarnos de cierta manera, tocarnos, modular los tonos de voz, aprehender, etc.) imposibles de producir en el hogar, o mejor dicho en los heterogéneos hogares, en los cuales acontece el hecho educativo, en el mejor de los casos, a través de una plataforma virtual. Misma reflexión con respecto a la cultura material de la escuela (pizarrón, bancos, sillas, paredes, murales, decoración, baldosas, mástil, cortinas, escaleras, relojes, busto de próceres, armarios, elementos de limpieza, vestimentas, etc.) la cual es claramente diferente a la del hogar en términos de producción de efectos y relaciones personales, materiales y simbólicas.

\section{Entre desafíos y posibilidades}

La pandemia no solo nos ofrece $y$, de alguna manera, fabrica ciertas certezas y determinadas incertidumbres. También abre un abanico de desafíos y posibilidades en los procesos educativos y pedagógicos. En primer lugar, más allá de las desigualdades que operan en el sistema educativo, las cuales posiblemente se agraven, la Covid-19 es una buena excusa para reflexionar críticamente sobre cómo funcionan las instituciones educativas presenciales, sus relaciones, sus espacios, sus tiempos, sus rituales, sus evaluaciones, sus acreditaciones, sus interacciones, sus aprendizajes y sus formas de enseñanzas; resituando y valorándolas como espacios públicos, colectivos y potencialmente emancipatorios. Asimismo, podemos aprender del propio proceso vinculado con la educación virtual masiva y cuasi obligatoria: identificar plataformas, posibilidades de acceso, nuevos lenguajes, nuevas formas de escritura y comunicación, nuevas formas de intercambio de experiencias, dificultades y obstáculos, nuevas formas de pensar el oficio del estudiante y el enseñante, etc. Aprender críticamente 
de lo que sucede con el mundo digital, nos puede permitir construir buenas preguntas que incluyan a los contenidos y a los conocimientos a transmitir pero, al mismo tiempo, que vayan más allá de ellos. Esto significa pensar a los contenidos como excusas para encontrarnos con los otros, más allá de la lógica de la mismidad (SKLIAR, 20I4), y compartir un proceso de crecimiento, autonomía crítica y agenciamiento. Animarnos a ir más allá de los contenidos definidos en las currículas o cambiar el foco de análisis podría ser la mayor enseñanza -y el mejor aprendizaje- de la pandemia. Por un lado, siguiendo a Tonucci se podría pensar:

la casa como un laboratorio donde descubrir cosas y los padres sean colaboradores de los maestros. Por ejemplo, cómo funciona una lavadora, tender la ropa, planchar, aprender a coser (...). La cocina, por ejemplo, es un taller de ciencia. Los niños deben aprender a cocinar. El maestro puede proponer que los alumnos cocinen un plato con su salsa y escriban la receta. Así estamos haciendo física, química, literatura y se puedo montar un libro virtual de recetas. Otra experiencia que me parece importan/te es que los niños hagan vídeos de su experiencia en casa. La otra experiencia, por supuesto, es la lectura. Como la escuela no consigue que los niños amen la lectura (...) debería preocuparse más, dar a sus alumnos el gusto de leer (...). Proponer a los niños que lean un libro debe ser un regalo, no un deber. Hay otra forma que es la lectura colectiva, de familia. Crear un teatro que tiene su horario y su lugar en la casa, y un miembro de la familia lee un libro como si fuera una telenovela. Media hora todos los días. Son propuestas que parecen poco escolares, pero todas tienen que ver con las disciplinas escolares. Estudiando las plantas de las casas se puede hacer una experiencia de geometría (...). Otra propuesta es que jueguen, eso es lo más importante. Que inventen juegos. Llamar a los abuelos para que aconsejen juegos, ellos fueron niños cuando los juegos había que inventarlos (TONUCCl, 2020).

Por otro lado, ir más allá de los contenidos disciplinares y aprovechar las condiciones materiales y simbólicas que produce la pandemia implicaría animarnos a reflexionar sobre varios problemas que posiblemente no sean objeto de un profundo tratamiento en las currículas oficiales. Dicho tratamiento podría generar ciudadanías más críticas, empáticas, solidarias y con un fuerte compromiso social. En este punto, construir buenas preguntas sería clave. Por ejemplo, podríamos preguntarnos con nuestros estudiantes sobre cómo funcionan las plataformas donde interactuamos y cuáles son las relaciones entre las mismas y las lógicas de mercado. ¿Qué actores se benefician comercial o políticamente con su uso? sería una pregunta pedagógicamente pertinente y altamente (con) movedora. Interrogarnos sobre las relaciones de poder, autoridad, exclusión, ocultamiento o desinformación ('fake news') que circulan desde y a partir de google y sus alianzas con diversos actores sociales y sus beneficios económicos serían interrogantes pedagógicamente iluminadores sobre cómo funciona el contexto material que nos permite conectarnos. Reflexionar sobre los formatos virtuales y digitales más allá de considerarlos meros soportes técnicos, asépticos, neutrales o estéticamente atractivos -y deliberadamente adictivos- sería una buena forma de problematizar en términos de poder, dominación, exclusión, posibilidades o resistencias el mundo que nos toca transitar $y$, en la medida de 
lo posible, transformar con el fin de producir escenarios educativos y sociales más "justos, comprometidos y democráticos" (GIROUX, 2003, p. 317). Interrogar los procesos políticos, económicos, financieros, diplomáticos, sociales, culturales, estéticos, sexuales, eróticos o ideológicos que se condensan de múltiples maneras a partir de la Covid-19 podría ser una buena lección sobre cómo funciona el poder, la hegemonía y los procesos de legitimación en términos micro o macropolíticos, cuestiones centrales de la teoría social crítica. Analizar la pandemia en clave interseccional, aspecto medular de la teoría social crítica, y preguntarnos por qué, en ciertos países, hay más muertes de personas pobres o negras, nos permitiría visibilizar "aquellos quienes a toda costa serán protegidos de la muerte y esas vidas que se considera que no vale la pena que sean protegidas de la enfermedad y la muerte" (BUTLER, 2020, p. 62). Preguntarnos por la fragilidad humana y su finitud, así como por las sensaciones y emociones (miedo, angustia, alegría, desazón, tristeza, etc.) que nos genera -y nos generan- esta situación; podría situar a la pandemia en una dimensión filosófica y, al mismo tiempo, profundamente ética. Estas y otras preguntas posibles pueden ser un buen desafío para desnaturalizar el mundo educativo y social, así como nuestras propias grillas interpretativas descomponiendo y nuevamente ordenando el universo pedagógico y socio-político, desorganizando; separando y re-adjuntando sus elementos en el punto de su más improbable relación (DIDIHUBERMAN, 2008).

\section{Consideraciones finales}

La Covid- 19 llegó a la Argentina en un contexto de fuerte desigualdad social. En dicho escenario las diferentes políticas educativas han realizado acciones concretas con el fin de garantizar el acompañamiento del proceso educativo $y$, al mismo tiempo, disminuir el impacto desigual que está potenciando la pandemia. En este contexto surgen certezas e incertidumbres sobre lo que acontece en los espacios virtuales $y$, al mismo tiempo, se abren un conjunto de posibilidades y desafíos. Los mismos se configuran en forma ambigua y contradictoria ya que la Covid-19 condensa una pluralidad de sentidos $y$, al mismo tiempo, de posibilidades de intervención en torno al quehacer educativo. Aunque la desigualdad social y educativa está aumentando producto de la Covid-19, el mismo puede convertirse en una muy buena excusa para generar resistencias, fugas de sentido y nuevas mediaciones (GIROUX, 2003) entre los docentes, los alumnos y otros actores de la trama educativa, resituando al conocimiento como parte de un proceso perspectivo, histórico, social, contingente, arbitrario e ideológicamente interesado. Vale decir, pensar la Covid-1 9 en clave crítica implica visibilizar los saberes y los efectos alrededor de la enfermedad como parte de procesos políticos, económicos, culturales, e ideológicamente interesados en donde la 'verdad' no puede analizarse independientemente de la

Olhar de professor, Ponta Grossa, v. 24, p. I-9, e-I5582.025, 2021.

Disponível em <https://revistas2.uepg.br/index.php/olhardeprofessor> 
Certezas, incertidumbres, posibilidades y desafios. La pandemia de Covid-1 9 en la educación en Argentina

libertad, la igualdad y la justicia. Parafraseando a Didi Huberman (2008) la Covid-I 9 nos puede ofrecer una posibilidad de 'montaje' de nuevas convenciones y prácticas -siempre contingentes, situadas y políticamente interesadas- que nos permitan imaginar escenas educativas más justas, democráticas, hospitalarias y menos violentas. Apostar críticamente por las posibilidades y desafíos desnaturalizando los modos en que organizamos, pensamos, actuamos y sentimos el mundo educativo y social puede ser uno de los mejores aprendizajes durante la pandemia.

\section{Referencias}

ARMUS, D. ¿Cómo se narra el coronavirus? Incertidumbres e historias globales. Revista Ñ , Buenos Aires. 22 de abril del 2020. Disponible en: https:/www.clarin.com/revista-enie/ideas/-narracoronavirus-incertidumbres-historias-globales_0_ot977nECw.html

BUTLER, J. El capitalismo tiene sus límites. In: AMADEO, P. (Org.). Sopa de Wuhan. La Plata: Editorial ASPO, p. 59-65, 2020.

CARDINI, A.; D'ALESSANDRE, V.; TORRE, E. Educar en tiempos de pandemia. Respuestas provinciales al COVID-I 9 en Argentina. Buenos Aires: CIPPEC, 2020.

CEPAL. Informe de la Comisión Económica para América Latina y el Caribe. Dimensionar los efectos del COVID-19 para pensar en la reactivación. 2020. Disponible en: https://www.cepal.org/es/publicaciones/45445-dimensionar-efectos-covid-19-pensar-la-reactivacion

DIDI-HUBERMAN, G. Cuando las imágenes toman posición. El ojo de la historia I. Madrid: Machado, 2008.

DUSSEL, I. La clase en pantuflas, 2020. Disponible en: https://www.youtube.com/watch?v=6xKvCtBC3Vs.

GIROUX, H. Pedagogía y política de la esperanza. Buenos Aires: Amorrortu editores, 2003.

MALPAS, J. Pensar topográficamente: Lugar, espacio y geografía, Documents d'Anàlisi Geogràfica. Barcelona, v. 6I, n. 2, p. 199-229, 20I5. DOI: https://doi.org/I 0.5565/rev/dag.297

RAMACCIOTTI, K. El acceso a la salud pública en la Argentina en tiempos de coronavirus, 2020. Disponible en: http://www.revistahcsm.coc.fiocruz.br/english/el-acceso-a-la-salud-publica-en-laargentina-en-tiempos-de-coronavirus/

SKLIAR, C. La cuestión de las diferencias en educación: tensiones entre inclusión y alteridad. Revista de Investigaciones, Manizales, v. I4, n. 24, p. I50-159, 2014. DOI: http://dx.doi.org//0.22383/ri.vl4i2.29

SOUTHWELL, M. Enunciación, interpelación y producción de políticas educativas recientes. Preguntas desde la teorización del populismo. Revista Fermentario, Montevideo, v. I, n. 12, p.65-82, 2018. DOI: https://doi.org//0.47965/fermen.12.1.6

Olhar de professor, Ponta Grossa, v. 24, p. I-9, e-15582.025, 2021.

Disponível em <https://revistas2.uepg.br/index.php/olhardeprofessor> 
TONUCCI, F. No perdamos este tiempo precioso dando deberes. El País, Madrid. I I de abril del 2020. Disponible en: https://elpais.com/sociedad/2020-04-II/francesco-tonucci-no-perdamos-este-tiempoprecioso-dando-deberes.html.

Recebido em: 28 de maio de 2020.

Versão corrigida recebida em: 14 de setembro de 2020.

Aceito em: 14 de setembro de 2020.

Publicado online em: 0 I de abril de 202I.

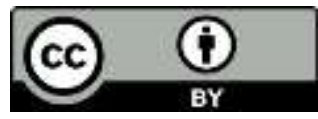

